\title{
Peripheral T-lymphocyte and natural killer cell population imbalance is associated with septic encephalopathy in patients with severe sepsis
}

\author{
CHENG-XIANG LU ${ }^{1,2}$, TING QIU ${ }^{3}$, HUA-SHENG TONG ${ }^{4}$, ZHI-FENG LIU ${ }^{4}$, LEI SU $^{1}$ and BIAO CHENG ${ }^{5}$ \\ ${ }^{1}$ Department of Intensive Care Unit, Affiliated General Hospital of Guangzhou Military Command of \\ Southern Medical University, Guangzhou, Guangdong 510515; Departments of ${ }^{2}$ Intensive Care Unit and ${ }^{3}$ Neurology, \\ Zhongshan Hospital Xiamen University, Xiamen, Fujian 361004; ${ }^{4}$ Department of Intensive Care Unit, \\ General Hospital of Guangzhou Military Command, Guangzhou, Guangdong 510010; ${ }^{5}$ Department of Plastic Surgery, \\ Affiliated General Hospital of Guangzhou Military Command of Southern Medical University, Guangzhou, \\ Guangdong 510515, P.R. China
}

Received May 13, 2015; Accepted December 21, 2015

DOI: $10.3892 /$ etm.2016.3000

\begin{abstract}
Septic encephalopathy (SE) is a diffuse cerebral dysfunction resulting from a systemic inflammatory response, and is associated with an increased risk of mortality. The pathogenesis of SE is complex and multifactorial, but unregulated immune imbalance may be an important factor. The current retrospective study examined the clinical data of 86 patients with severe sepsis who were admitted to the Intensive Care Unit at Zhongshan Hospital, Xiamen University (Xiamen, China) from January, 2014 to January, 2015. The patients were assigned to $\mathrm{SE}$ and non-SE patient groups according to the presence or absence of SE. The proportion of T-lymphocyte subsets and natural killer (NK) cells in the immune cell population, representing the function of the immune system, were analyzed for their association with SE and compared with other clinical predictors and biomarkers. The incidence of SE in the patients was $39.5 \%$, and this group demonstrated higher mortality rates (38 vs. $10 \%$ in non-SE patients; $\mathrm{P}=0.001$ ). Univariate analysis revealed that the SE patients reported a lower percentage of cluster of differentiation $4^{+}\left(\mathrm{CD} 4^{+}\right)$T-lymphocytes
\end{abstract}

Correspondence to: Dr Biao Cheng, Department of Plastic Surgery, Affiliated General Hospital of Guangzhou Military Command of Southern Medical University, 111 Liu Hua Road, Guangzhou, Guangdong 510515, P.R. China

E-mail: 958028065@qq.com; chengbiaocheng@163.com

Dr Lei Su, Department of Intensive Care Unit, Affiliated General Hospital of Guangzhou Military Command of Southern Medical University, 111 Liu Hua Road, Guangzhou, Guangdong 510515, P.R China

E-mail: mynamelsulei@sina.com; slei_icu@163.com

Key words: septic encephalopathy, mortality, immune imbalance, severe sepsis, CD4 ${ }^{+}$T-lymphocytes, natural killer cell, regression, predictor
(51.67 \pm 7.12 vs. $60.72 \pm 3.70 \%$ in non-SE patients; $\mathrm{P}<0.01)$, a lower $\mathrm{CD} 4^{+} /$cluster of differentiation $8^{+}\left(\mathrm{CD} 8^{+}\right)$ratio $(1.59 \pm 0.32$ vs. $1.85 \pm 0.26 \%$ in non-SE patients; $\mathrm{P}<0.01)$ and a higher percentage of NK cells $(11.80 \pm 1.44$ vs. $9.19 \pm 2.36 \%$ in non-SE patients; $\mathrm{P}<0.01)$. Using a binary logistic regression model, the Acute Physiology and Chronic Health Evaluation II score and the percentage of $\mathrm{CD} 4^{+} \mathrm{T}$-lymphocytes were demonstrated to be independently associated with SE (respectively, $\mathrm{P}=0.012$ and $\mathrm{OR}, 4.763 ; \mathrm{P}=0.005$ and $\mathrm{OR}, 0.810$ ). An area under the curve analysis of a receiver operating characteristic curve of the two indicators revealed that these were equally powerful measures in prediction of SE $(\mathrm{Z}=1.247, \mathrm{P}>0.05)$. The present results confirm that SE leads to higher mortality in patients with severe sepsis, and demonstrate that immune imbalance is important in the development of SE. The proportion of CD4 ${ }^{+}$ T-lymphocytes present were revealed in the current study to be a powerful predictor of SE in patients with severe sepsis.

\section{Introduction}

Septic encephalopathy (SE), defined as altered mental status and presenting with behavioral or cognitive abnormalities, is one of the most common complications in septic patients and is likely to be under-diagnosed (1). SE is associated with a higher mortality rate and is also a reliable indicator of a poor clinical outcome $(2,3)$. Numerous animal and human studies have been performed to elucidate the etiology of SE (4-6) but, at present, the pathogenesis of SE is unknown. However, several potential mechanisms have been investigated, such as alterations to the blood-brain barrier (BBB), reduction in cerebral blood flow, the inflammatory response and activation of microglia and astrocytes and amino acid imbalance (7-10). The impact of an increased inflammatory response on the central nervous system (CNS) has been a key focus of investigation during the last two decades. Excessive inflammation, often termed a 'cytokine storm', characterizes early sepsis (11-14). As sepsis progresses, patients frequently develop multiple organ dysfunction and nosocomial infections 
by opportunistic pathogens (15-17) and the nervous system is particularly vulnerable to damage in response to systemic inflammation. Previous studies (11-13) suggest that patients with sepsis present with an immune factor imbalance, and there is a clear connection between immune imbalance and the occurrence of SE. Extensive previous evidence indicates that anti-inflammatory action in the brain and the resolution of neuroinflammation requires balance between the various branches of the immune system (18-20). An imbalance within the immune system and the systemic inflammation that results may promote CNS damage. The present retrospective study aimed to investigate the role of immune imbalance in SE, in addition to its effect on prognosis, using clinical data from patients with severe sepsis.

\section{Subjects and methods}

Ethics statement. The present study was approved by the Medical Ethics Committee of Zhongshan Hospital at Xiamen University (Xiamen, China). The present study did not increase the patient's medical expenses or pain and all research materials and results were used for research purposes. The requirement for informed consent was waived by the Medical Ethics Committee as the present study was an observational, respective study using a database from which the patients identifying information had been removed.

Subjects. Severe sepsis was defined as sepsis combined with sepsis-induced organ dysfunction or tissue hypoperfusion, in accordance with criteria set out during the 2001 SCCM/ESICM/ACCP/ATS/SIS International Sepsis Definition Conference (21). Symptoms of SE include somnolence, stupor, coma, confusion, disorientation, agitation, irritability and a decreased score on the Glasgow Coma Scale. SE was defined as an altered mental status with behavioral or cognitive abnormalities, but there is no current unified standard for SE diagnoses $(22,23)$. Patients suffering from the following underlying conditions that may affect brain and CNS function and symptomatic diagnosis were excluded: i) Intracranial organic diseases; ii) severe nutritional deficiency; iii) hypoglycemia; iv) hypernatremia; v) hepatic encephalopathy; and vi) a history of exposure to drugs, toxic substances, alcohol, industrial agents, heavy metals or any substance established to cause altered consciousness.

In the present study, 127 patients demonstrating severe sepsis were admitted to the Intensive Care Unit of Zhongshan Hospital at Xiamen University between January 2014 and January 2015. Of these patients, 41 patients were excluded due to the aforementioned exclusion criteria, predominantly linked to exposure to sedative drugs or intracranial organic disease, thus 86 patients were analyzed in the current study. In total, 57 men and 29 women were included, with an average age of 58.7 years. During their hospital stay, 34 patients developed SE although 52 patients did not, and patients were subsequently assigned to the SE and non-SE groups. Eighteen patients across the two groups succumbed to the disease during the 28-day study, representing a frequency of $20.93 \%$ (18/86 patients).

Treatment. The patients were treated with a standardized therapy based on the Severe Sepsis Campaign sepsis treatment guidelines (24). This therapy involved fluid resuscitation, antibiotic therapy, identification and control of infected tissue, mechanical ventilation, renal replacement, glucose control and supportive treatments, such as vasoactive drugs and steroid therapies.

Data collection. The medical record for each patient was reviewed. Patient demographics, mean arterial pressure, heart rate, duration of ventilator treatment, Acute Physiology and Chronic Health Evaluation (APACHE) II score, Sequential Organ Failure Assessment (SOFA) score and outcome were recorded. APACHE II score and SOFA score at the time of admission to the Intensive Care Unit were also calculated.

Blood samples were obtained for routine examination of metrics, including liver and kidney function, such as alanine aminotransferase (ALT), bilirubin, activated partial thromboplastin time and serum creatinine levels; blood glucose; 6-h lactate clearance; B-type natriuretic peptide; blood gas analysis, including reporting of $\mathrm{pH}$, arterial partial pressure of oxygen, arterial partial pressure of carbon dioxide and bicarbonate; brain injury markers, including levels of neuron specific enolase (NSE) and S-100 $\beta$ protein; and immune parameters, including white blood cell count, $\mathrm{C}$-reactive protein, procalcitonin and the percentages of cluster of differentiation $4^{+}$ $\left(\mathrm{CD}^{+}\right)$and cluster of differentiation $8^{+}\left(\mathrm{CD} 8^{+}\right)$T-lymphocytes and natural killer (NK) cells present. Flow cytometery (Elite XL4; Beckman Coulter, Inc., Brea, CA, USA ) was used to detect the proportion of $\mathrm{CD}^{+}$and $\mathrm{CD}^{+} \mathrm{T}$-lymphocytes, to calculate the $\mathrm{CD} 4^{+} / \mathrm{CD}^{+}$ratio. Samples were collected in a test tube at $4^{\circ} \mathrm{C}$ containing tripotassium hydrogen ethylenediaminetetraacetate and analyzed within $30 \mathrm{~min}$ of collection.

The specimens were collected from the sputum in the lower respiratory tract using fiberbronchoscopy (Olympus BF P-30; Olympus Corporation, Tokyo, Japan), from wound excretions, from urine and from blood for cultivation and diagnosis of pathogenic bacteria in a $37^{\circ} \mathrm{C}$ incubator.

Statistical analysis. Statistical analysis was conducted using SPSS v. 19.0 software (IBM SPSS, Armonk, NY, USA). Measurement data were expressed as mean \pm SD and compared using independent t-tests. Enumeration data were compared using a $\chi^{2}$ test or with Fisher's exact test, as appropriate. For detection of correlation, Pearson's correlation analysis was performed. $\mathrm{P}<0.05$ was considered to indicate a statistically significant difference. Statistically significant variables were subsequently analyzed using a binary logistic regression to identify the risk factors associated with SE. Only variables markedly associated with SE $(\mathrm{P}<0.05)$ were included in the final model. Receiver operating characteristic (ROC) curves and the area under the curves (AUCs) were examined in significant variables associated with SE, to determine a cut-off level and to predict mortality.

\section{Results}

Baseline data of the patients. During the period of the present study, 127 patients with severe sepsis were initially admitted, 86 of whom were included in the study. Patient characteristics of the two groups are provided in Table I. No significant differences were identified between the 
Table I. Baseline characteristics of the SE and non-SE groups.

\begin{tabular}{|c|c|c|c|}
\hline Characteristics & SE group $(n=34)$ & Non-SE group $(n=52)$ & P-value \\
\hline Age in years, mean $\pm \mathrm{SD}$ & $59.15 \pm 8.80$ & $58.39 \pm 8.14$ & 0.69 \\
\hline Male/female, $\mathrm{n}$ & $24 / 10$ & $33 / 19$ & 0.49 \\
\hline \multicolumn{4}{|l|}{ Underlying diseases, n (\%) } \\
\hline Chronic lung disease & $9(26)$ & $11(21)$ & 0.57 \\
\hline Hypertension & $8(24)$ & $16(31)$ & 0.46 \\
\hline Hyperlipidemia & $10(29)$ & $17(68)$ & 0.75 \\
\hline Coronary artery disease & $4(12)$ & $8(15)$ & 0.76 \\
\hline Chronic liver disease & $3(9)$ & $9(17)$ & 0.35 \\
\hline Chronic renal disease & $2(6)$ & $2(4)$ & 0.65 \\
\hline Diabetes mellitus & $11(32)$ & $19(37)$ & 0.69 \\
\hline \multicolumn{4}{|l|}{ Clinical presentation, mean \pm SD } \\
\hline Mean arterial pressure, $\mathrm{mmHg}$ & $78.52 \pm 7.15$ & $79.23 \pm 5.93$ & 0.62 \\
\hline Heart rate, beats/min & $104.71 \pm 15.79$ & $109.21 \pm 15.03$ & 0.19 \\
\hline Ventilator treatment duration, days & $13.12 \pm 3.89$ & $8.28 \pm 3.32$ & $<0.01^{\mathrm{a}}$ \\
\hline 28-day mortality, n (\% of cases) & $13(38)$ & $5(10)$ & $0.001^{\mathrm{a}}$ \\
\hline \multicolumn{4}{|l|}{ Disease severity index, mean \pm SD } \\
\hline APACHE II score & $21.74 \pm 2.96$ & $16.25 \pm 2.62$ & $<0.01^{\mathrm{a}}$ \\
\hline SOFA score & $8.21 \pm 1.45$ & $5.38 \pm 1.84$ & $<0.01^{\mathrm{a}}$ \\
\hline
\end{tabular}

Data presented as $\mathrm{n}(\%)$ were analyzed by a $\chi^{2}$ test or Fisher's exact test when theoretical frequency $<5$. ${ }^{a} \mathrm{P}<0.05$, SE vs. non-SE group. SE, septic encephalopathy; SD, standard deviation; APACHE, Acute Physiology and Chronic Health Evaluation; SOFA, Sequential Organ Failure Assessment.

Table II. Sources of infection in the SE and non-SE groups, expressed as n (\%).

\begin{tabular}{|c|c|c|c|}
\hline Sources of infection & SE group $(n=34)$ & Non-SE group $(n=52)$ & P-value \\
\hline \multicolumn{4}{|l|}{ Organ system infected } \\
\hline Respiratory system & $10(29)$ & $17(33)$ & 0.75 \\
\hline Digestive system & $12(35)$ & $20(39)$ & 0.77 \\
\hline Urinary system & $6(18)$ & $8(15)$ & 0.78 \\
\hline Skin and soft tissue & $4(12)$ & $5(10)$ & 0.74 \\
\hline Other & $2(6)$ & $2(4)$ & 0.65 \\
\hline Concurrent bacteremia episodes & $6(18)$ & $9(17)$ & 0.97 \\
\hline \multicolumn{4}{|l|}{ Causative pathogens } \\
\hline Gram-positive & $15(44)$ & $25(48)$ & 0.72 \\
\hline Staphylococcus aureus & $8(23)$ & $11(21)$ & 0.80 \\
\hline Streptococcus pneumonia & $1(3)$ & $4(8)$ & 0.64 \\
\hline Enterococcus faecium & $5(15)$ & $6(12)$ & 0.75 \\
\hline Enterococcus faecalis & $1(3)$ & $4(8)$ & 0.64 \\
\hline Gram-negative & $24(71)$ & $39(75)$ & 0.65 \\
\hline Acinetobacterbaum anni & $7(21)$ & $13(25)$ & 0.64 \\
\hline Pseudomonas aeruginosa & $5(15)$ & $10(19)$ & 0.59 \\
\hline Escherichia coli & $4(12)$ & $8(15)$ & 0.76 \\
\hline Klebsiella pneumoniae & $4(11.8)$ & $5(9.6)$ & 0.74 \\
\hline Proteus mirabilis & $2(5.9)$ & $2(3.8)$ & 0.65 \\
\hline Entembacter cloacae & $2(5.9)$ & $1(1.9)$ & 0.56 \\
\hline Epiphyte & $4(11.8)$ & $5(9.6)$ & 0.74 \\
\hline
\end{tabular}

Data were analyzed by a $\chi^{2}$ test or Fisher's exact test when theoretical frequency $<5$. SE, septic encephalopathy. 
Table III. Laboratory data of the SE and non-SE groups, presented as mean \pm SD.

\begin{tabular}{|c|c|c|c|}
\hline Laboratory variable & SE group $(n=34)$ & Non-SE group $(n=53)$ & P-value \\
\hline \multicolumn{4}{|l|}{ Biochemistry } \\
\hline Glucose, mmol/l & $9.63 \pm 3.21$ & $9.20 \pm 2.94$ & 0.52 \\
\hline ALT, U/1 & $156.79 \pm 33.57$ & $98.69 \pm 38.12$ & $<0.01^{\mathrm{a}}$ \\
\hline Creatinine, $\mathrm{mmol} / \mathrm{l}$ & $86.49 \pm 24.62$ & $79.28 \pm 22.04$ & 0.16 \\
\hline $6 \mathrm{~h}$ lactate clearance, $\%$ & $16.71 \pm 7.73$ & $18.15 \pm 8.08$ & 0.41 \\
\hline Total bilirubin, mmol/l & $13.28 \pm 4.94$ & $12.80 \pm 4.52$ & 0.64 \\
\hline $\mathrm{BNP}, \mathrm{pg} / \mathrm{ml}$ & $1224.20 \pm 586.99$ & $1042.89 \pm 507.23$ & 0.13 \\
\hline $\mathrm{PaO}_{2}, \mathrm{mmHg}$ & $77.20 \pm 17.92$ & $81.19 \pm 20.91$ & 0.36 \\
\hline APTT, sec & $38.56 \pm 6.87$ & $40.08 \pm 7.59$ & 0.36 \\
\hline $\mathrm{NSE}, \mu \mathrm{g} / \mathrm{l}$ & $10.02 \pm 1.48$ & $9.86 \pm 0.91$ & 0.58 \\
\hline $\mathrm{S}-100 \beta, \mu \mathrm{g} / 1$ & $1.21 \pm 0.15$ & $0.98 \pm 0.20$ & $<0.01^{\mathrm{a}}$ \\
\hline \multicolumn{4}{|l|}{ Inflammatory markers } \\
\hline $\mathrm{WBC}, \mathrm{n} \times 10^{9} / 1$ & $15.89 \pm 6.51$ & $16.39 \pm 7.24$ & 0.75 \\
\hline CRP, mg/l & $230.99 \pm 67.59$ & $205.99 \pm 102.81$ & 0.18 \\
\hline PCT, ng/ml & $10.69 \pm 5.41$ & $9.97 \pm 4.94$ & 0.53 \\
\hline $\mathrm{CD}^{+}, \%$ of total cells & $51.67 \pm 7.12$ & $60.72 \pm 3.70$ & $<0.01^{\mathrm{a}}$ \\
\hline $\mathrm{CD}^{+}, \%$ of total cells & $32.92 \pm 2.48$ & $33.26 \pm 2.71$ & 0.56 \\
\hline $\mathrm{CD}^{+} / \mathrm{CD}^{+}$ & $1.59 \pm 0.32$ & $1.85 \pm 0.26$ & $<0.01^{\mathrm{a}}$ \\
\hline $\mathrm{NK}, \%$ of total cells & $11.80 \pm 1.44$ & $9.19 \pm 2.36$ & $<0.01^{\mathrm{a}}$ \\
\hline
\end{tabular}

SE, septic encephalopathy; SD, standard deviation; ALT, alanine aminotransferase; BNP, B-type natriuretic peptide; $\mathrm{PaO}_{2}$, arterial partial pressure of oxygen; APTT, activated partial thromboplastin time; NSE, neuron-specific enolase; WBC, white blood cells; CRP, C-reactive protein; PCT, procalcitonin; $\mathrm{CD}^{+}$, cluster differentiation $4^{+} \mathrm{T}$ helper cells; $\mathrm{CD} 8^{+}$, cluster differentiation $8^{+} \mathrm{T}$ helper cells; $\mathrm{NK}$, natural killer cells. ${ }^{\mathrm{a}} \mathrm{P}<0.05$, SE vs. non-SE group.

Table IV. Correlation between immune parameters and sepsis severity.

\begin{tabular}{|c|c|c|c|c|c|c|c|c|}
\hline \multirow[b]{2}{*}{ Immune parameter } & \multicolumn{4}{|c|}{ APACHE II } & \multicolumn{4}{|c|}{ SOFA } \\
\hline & $\mathrm{r}$ & P-value & $\mathrm{R}^{2}$ & $95 \% \mathrm{CI}$ & $\mathrm{r}$ & P-value & $\mathrm{R}^{2}$ & $95 \% \mathrm{CI}$ \\
\hline $\mathrm{CD}^{+}$ & -0.854 & $<0.01$ & 0.729 & -0.905 to -0.787 & -0.878 & $<0.01$ & 0.771 & -0.914 to -0.827 \\
\hline $\mathrm{CD}^{+} / \mathrm{CD}^{+}$ & -0.824 & $<0.01$ & 0.679 & -0.883 to -0.741 & -0.853 & $<0.01$ & 0.728 & -0.909 to -0.783 \\
\hline NK & 0.816 & $<0.01$ & 0.666 & 0.756 to 0.869 & 0.871 & $<0.01$ & 0.759 & 0.803 to 0.920 \\
\hline
\end{tabular}

APACHE, Acute Physiology and Chronic Health Evaluation; SOFA, Sequential Organ Failure Assessment; r, correlation coefficient; $\mathrm{R}^{2}$, coefficient of determination; CI, confidence interval; $\mathrm{CD} 4^{+}$, cluster differentiation $4^{+} \mathrm{T}$ helper cells; CD $8^{+}$, cluster differentiation $8^{+}$ T-helper cells; NK, natural killer cells.

groups in age, gender, underlying diseases, mean arterial pressure or heart rate $(\mathrm{P}>0.05)$. However, duration of ventilator treatment and 28-day mortality were significantly higher in the SE group compared to the non-SE group $(13.12 \pm 3.89$ vs. $8.28 \pm 3.32$ days, $\mathrm{P}<0.01$; and 38 vs. $10 \%$, $\mathrm{P}=0.001$, respectively). With regard to the disease severity index, the SE group had higher APACHE II and SOFA scores than the non-SE group $(21.74 \pm 2.96$ vs. $16.25 \pm 2.62, \mathrm{P}<0.01$; and $8.21 \pm 1.45$ vs. $5.38 \pm 1.84, \mathrm{P}<0.01$, respectively), indicating a greater degree of organ dysfunction.

Table II reports the sources of infection and the causative microorganisms in the two groups of patients. No significant difference was identified in the infection source between the groups: the SE group did not report significantly different numbers of patients with gram-positive cocci, gram-negative bacilli or epiphyte infection compared with the non-SE group, nor any different frequency of each microorganism $(\mathrm{P}>0.05)$.

Laboratory data are shown in Table III. A significant increase in the serum levels of ALT and S-100 $\beta$ protein in the SE group compared to the non-SE group was revealed using independent t-tests $(156.79 \pm 33.57$ vs. $98.69 \pm 38.12 \mathrm{U} / 1, \mathrm{P}<0.01$; and $1.21 \pm 0.15$ vs. $0.98 \pm 0.20 \mu \mathrm{g} / 1, \mathrm{P}<0.01$, respectively), using the Karman-Worblewski method (25). In regard to inflammatory markers and immune parameters, the percentage of $\mathrm{CD}^{+}{ }^{+} \mathrm{T}$ lymphocytes and the $\mathrm{CD} 4^{+} / \mathrm{CD}^{+}$ratio were 
Table V. Correlation between immune parameters and brain injury severity.

\begin{tabular}{|c|c|c|c|c|c|c|c|c|}
\hline \multirow[b]{2}{*}{ Immune parameter } & \multicolumn{4}{|c|}{ NSE } & \multicolumn{4}{|c|}{ S- $100 \beta$} \\
\hline & $\mathrm{r}$ & P-value & $\mathrm{R}^{2}$ & $95 \% \mathrm{CI}$ & $\mathrm{r}$ & $\mathrm{P}$-value & $\mathrm{R}^{2}$ & $95 \% \mathrm{CI}$ \\
\hline $\mathrm{CD} 4^{+}$ & -0.738 & $<0.01$ & 0.545 & -0.828 to -0.613 & -0.696 & $<0.01$ & 0.484 & -0.863 to -0.457 \\
\hline $\mathrm{CD}^{+} / \mathrm{CD}^{+}$ & -0.872 & $<0.01$ & 0.760 & -0.919 to -0.811 & -0.719 & $<0.01$ & 0.517 & -0.886 to -0.484 \\
\hline NK & 0.683 & $<0.01$ & 0.466 & 0.555 to 0.778 & 0.795 & $<0.01$ & 0.632 & 0.607 to 0.930 \\
\hline
\end{tabular}

NSE, neuron specific enolase; $r$, correlation coefficient; $\mathrm{R}^{2}$, coefficient of determination; $\mathrm{CI}$, confidence interval; $\mathrm{CD}^{+}$, cluster differentiation $4^{+} \mathrm{T}$ helper cells; $\mathrm{CD} 8^{+}$, cluster differentiation $8^{+} \mathrm{T}$-helper cells; NK, natural killer cells.

Table VI. Logistic regression analysis of risk factors of septic encephalopathy.

\begin{tabular}{lcccccr}
\hline Risk factor & B & SE & Wald & P-value & OR & \multicolumn{1}{c}{$95 \%$ CI } \\
\hline APACHE II & 1.561 & 0.625 & 6.244 & 0.012 & 4.763 & $1.400-16.202$ \\
CD4 $^{+}$ & -0.211 & 0.076 & 7.731 & 0.005 & 0.810 & $0.698-0.940$
\end{tabular}

B, partial regression coefficient; SE, standard error; OR, odds ratio; CI, confidence interval; APACHE, Acute Physiology and Chronic Health Evaluation; $\mathrm{CD}^{+}$, cluster differentiation $4^{+}$T-helper cells.

Table VII. Receiver operating characteristic curve analysis of independent risk factors in diagnosing septic encephalopathy.

\begin{tabular}{lcccc}
\hline Risk factor & AUC & SE & $95 \%$ CI & P-value \\
\hline APACHE II & 0.919 & 0.028 & $0.864-0.973$ & $<0.001$ \\
CD4 $^{+}$ & 0.855 & 0.043 & $0.771-0.939$ & $<0.001$ \\
\hline
\end{tabular}

AUC, area under the curve; SE, standard error; CI, confidence interval; APACHE, Acute Physiology and Chronic Health Evaluation; $\mathrm{CD} 4^{+}$, cluster differentiation $4^{+}$T-helper cells.

significantly lower in the SE group (51.67 \pm 7.12 vs. $60.72 \pm 3.70 \%$ in the non-SE group, $\mathrm{P}<0.01$; and $1.59 \pm 0.32$ vs. $1.85 \pm 0.26$ in the non-SE group, $\mathrm{P}<0.01$, respectively), while the percentage of NK cells was significantly higher in the SE group compared to the non-SE group $(11.80 \pm 1.44$ vs. $9.19 \pm 2.36 \%, \mathrm{P}<0.01)$. No significant differences were identified in the other laboratory variables examined $(\mathrm{P}>0.05)$.

Correlation between immune parameters and disease severity. The percentage of $\mathrm{CD} 4^{+} \mathrm{T}$ lymphocytes, the $\mathrm{CD} 4^{+} / \mathrm{CD} 8^{+}$ratio and the percentage of NK cells were significantly different between the SE and non-SE groups (Table III). Thus, additional correlation analysis between these immune parameters and disease severity was conducted. Based on the results of Pearson's correlation analysis (Tables IV and V), the percentage of $\mathrm{CD} 4^{+} \mathrm{T}$-lymphocytes, the $\mathrm{CD} 4^{+} / \mathrm{CD}^{+}$ratio and the percentage of NK cells demonstrated a marked correlation with APACHE II scores $(\mathrm{r}=-0.854,-0.824$ and 0.816 , respectively; $\mathrm{P}<0.01)$, SOFA scores $(\mathrm{r}=-0.878,-0.853$ and 0.871 , respectively; $\mathrm{P}<0.01)$, NSE levels $(\mathrm{r}=-0.738,-0.872$ and 0.683 , respectively; $\mathrm{P}<0.01)$ and $\mathrm{S}-100 \beta$ protein levels $(\mathrm{r}=-0.696$,

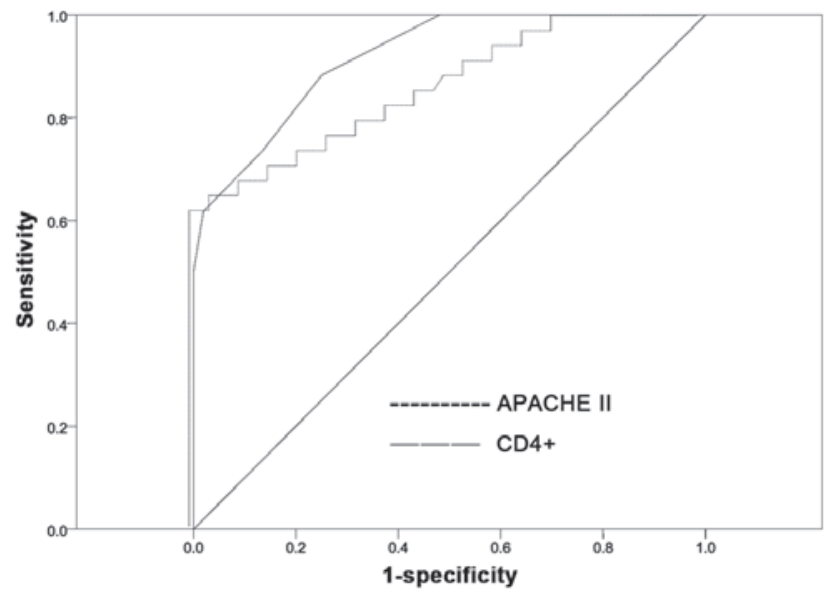

Figure 1. Comparison receiver operating characteristic curve of $\mathrm{CD} 4^{+}$with APACHE II score for predicting septic encephalopathy. APACHE, Acute Physiology and Chronic Health Evaluation; $\mathrm{CD}^{+}$, cluster differentiation $4^{+}$ T-helper cells.

-0.719 and 0.795 , respectively; $\mathrm{P}<0.01)$. These analyses revealed that the percentage of $\mathrm{CD} 4^{+} \mathrm{T}$ lymphocytes and NK cells and the $\mathrm{CD}^{+} / \mathrm{CD} 8^{+}$ratio were correlated with sepsis and brain injury severity. The results of the present analyses also indicated that the most marked correlation in sepsis severity was between the percentage of $\mathrm{CD} 4^{+} \mathrm{T}$ lymphocytes and SOFA score $\left(\mathrm{R}^{2}=0.771\right)$ and, in brain injury severity, was between the $\mathrm{CD}^{+} / \mathrm{CD} 8^{+}$ratio and NSE levels $\left(\mathrm{R}^{2}=0.760\right)$.

Prediction of SE. APACHE II and SOFA scores, serum ALT and $\mathrm{S}-100 \beta$ protein levels, the percentage of $\mathrm{CD}^{+}{ }^{+} \mathrm{T}$ lymphocytes and NK cells and the $\mathrm{CD} 4^{+} / \mathrm{CD}^{+}$ratio were significantly different between the two groups and may be used as predictive factors. However, subsequent to use of a binary logistic 
Table VIII. Prediction of septic encephalopathy.

\begin{tabular}{lcccc}
\hline Risk factor & Maximum Youden's index & Best cut-off value & Sensitivity $(\%)$ & Specificity $(\%)$ \\
\hline APACHE II & 1.632 & 18.500 & 88.2 & 75.0 \\
CD4 $^{+}$ & 1.580 & 55.655 & 67.6 & 90.4 \\
\hline
\end{tabular}

APACHE, Acute Physiology and Chronic Health Evaluation; CD4 ${ }^{+}$, cluster differentiation $4^{+}$T-helper cells.

regression analysis (using the forward conditional method), performed with 'SE presence or absence' as a dependent variable and all the predictors as independent variables, only the APACHE II score and the percentage of $\mathrm{CD}^{+}$T-lymphocytes $(\mathrm{P}=0.012$ and $\mathrm{OR}, 4.763 ; \mathrm{P}=0.005$ and $\mathrm{OR}, 0.810$, respectively) entered the final equation, demonstrating that they were independently associated with SE (Table VI).

The effectiveness of these variables in predicting SE was evaluated by assessing the AUC of each ROC curve (Table VII; Fig. 1). The AUCs for the percentage of $\mathrm{CD}^{+} \mathrm{T}$ lymphocytes and APACHE II score were 0.919 and 0.855 , respectively $(\mathrm{P}<0.001)$, reflecting good discrimination. A Z-test was subsequently used to compare the predictive ability of these variables, identifying no significant difference between the AUCs of the percentage of $\mathrm{CD}^{+} \mathrm{T}$ lymphocytes and APACHE II score $(\mathrm{Z}=1.247, \mathrm{P}=0.212)$, revealing that these were equally powerful measures in the prediction of SE ( $P>0.05)$. Based on the ROC curve and the maximum Youden's index, the most appropriate cut-off value was selected. With regard to the percentage of $\mathrm{CD} 4^{+} \mathrm{T}$ lymphocytes, the most appropriate cut-off value for predicting SE was $55.655 \%$, corresponding to the sensitivity and specificity values of 67.6 and $90.4 \%$, respectively. With regard to APACHE II score, the most appropriate cut-off value for predicting SE was 18.500 , corresponding to the sensitivity and specificity values of 88.2 and $75.0 \%$, respectively (Table VIII).

\section{Discussion}

$\mathrm{SE}$ is an acute neurological dysfunction that results from sepsis and is associated with high morbidity and mortality. During sepsis, the brain is vulnerable, and encephalopathy frequently results but is not commonly identified $(26,27)$. According to previous studies, the incidence of SE following severe sepsis varies from $9-71 \%$ with a mortality frequency of $~ 50 \%(2,28)$, dependent on the method used to grade altered mental status $(3,29)$. In the present study, SE resulted in $40 \%$ of severe sepsis cases, with a mortality of $38 \%$. Although the incidence and mortality are inconsistent across studies, the brain is sensitive to sepsis, and SE often has severe consequences $(2,28)$. SE should therefore be recognized as an indicator of poor prognosis in patients with sepsis, inducing prompt and aggressive therapy.

APACHE II and SOFA scores have been applied to critically ill patients to evaluate the severity of SE and clinical outcomes. Previous findings have shown that the severity of encephalopathy was associated with the global severity of disease, as assessed by APACHE II score or SOFA, and mortality rates $(1,2)$. In the present study, the mortality of septic patients significantly increased with increased APACHE II and SOFA scores, which is consistent with previous reports (30), supporting an association of SE with an increased mortality risk in patients with severe sepsis.

The present study indicated that patients with SE required a greater duration of ventilator treatment, revealing more severe respiratory failure. In clinical practice, patients with disturbance of consciousness are prone to respiratory failure due to an inability to protect the airway and respiratory drive. During a period of hypoxemia that occurs prior to respiratory failure, a greater degree of brain injury may be generated. The present analyses demonstrated a significantly increased level of ALT in patients with SE. Sepsis is often associated with multiple organ failure and numerous abnormal biochemical indicators, which indicates there may be a complex inherent association between individual organ failure and an amplification process that hastens injury to other organs. This could be seen to explain the increased mortality in the SE group.

The pathophysiology of SE is complex, and may include activation of the inflammatory response, microglia and astrocytes, alteration in the BBB, amino acid disruption, brain hypoperfusion/ischemia and translocation of neurotoxic molecules (7-10). An upregulated inflammatory response is recognized as an integral contributor to SE. Previous studies have comprehensively investigated the effect of infection on CNS. However, the severity of SE is reportedly not associated with infection by specific microorganisms, nor groups thereof (31). Furthermore, inflammatory mediators, including interleukin- 1 and tumor necrosis factor- $\alpha$ and oxidative stress have a critical role in the abnormal neurotransmitter composition and impaired neuronal and microglia function (32-34). Reduced hepatic clearance and increased neurotoxic amino acids in sepsis associated with muscle proteolysis also contribute to the development of brain dysfunction $(35,36)$. The S-100 $\beta$ protein has been previously employed as an indicator of astrocyte activation and injury, and as a marker for brain injury in SE (37,38); however, not all studies concur with this finding $(39,40)$. In the present study, $S-100 \beta$ protein was significantly higher in SE patients, but regression analysis indicated that this is not the most reliable indicator for predicting SE, a finding that was consistent with previously conflicting findings (37-40). Additional evaluation of the direct effect of brain injury to SE is required to clarify the most effective markers.

Lipopolysaccharide stimulation has previously been reported to induce the release of proinflammatory and anti-inflammatory cytokines, in addition to their receptors, from a number of nervous system-associated cells, including neurones, astrocytes and microglia $(41,42)$. This coexpression of proinflammatory and anti-inflammatory 
cytokines indicates that the immune system is highly regulated within the brain. Concordantly, in sepsis survivors, the initial proinflammatory burst often develops into immune suppression, characterized by T-cell dysfunction and adaptive immune suppression accompanied by innate immune system activation (43-45) This immune imbalance develops throughout sepsis and study in this area has made significant progress (46). Reduction in the number of circulating $\mathrm{CD}^{+} \mathrm{T}$ lymphocytes and their shift to a Th2 phenotype are indicative of aspects of sepsis-induced adaptive immunosuppression (47). The association between clinical course of contradiction and poor prognosis of patients with sepsis and the decline of peripheral blood $\mathrm{CD} 4^{+} \mathrm{T}$ lymphocytes has been established in a majority of patients with sepsis $(48,49)$. Furthermore, NK cells, a type of cytotoxic lymphocyte, are likely to be involved in the antibacterial response of the innate immune system due to their ability to recognize pathogen-associated molecular patterns $(50,51)$. Findings of a previous study have shown that patients with the highest NK cell number have the lowest probability of survival (52). In the present study, the percentage of $\mathrm{CD} 4^{+} \mathrm{T}$ lymphocytes and the $\mathrm{CD} 4^{+} / \mathrm{CD}^{+}$ratio were significantly lower and the percentage of NK cells was significantly higher in the SE group than in the non-SE group, suggesting adaptive immune suppression and innate immune activation of patients. The present results are comparable with previous studies and indicate a highly significant functional imbalance of immune cells in patients with SE, which may be crucial in the development of encephalopathy.

$\mathrm{CD}^{+} \mathrm{T}$ lymphocytes are particularly vulnerable to apoptotic death in polymicrobial sepsis models, according to previous studies $(43,53)$. In addition, the response of $\mathrm{T}$ lymphocytes to continuously elevated serum levels of anti-inflammatory cytokines was an improved predictor of mortality than proinflammatory cytokines in patients with severe sepsis (54), which are typically used. In the current study, only the percentage of $\mathrm{CD} 4^{+} \mathrm{T}$ lymphocytes and APACHE II score were determined to be similarly accurate predictors of clinical outcome, based on the regression analysis, when compared with the $\mathrm{CD} 4^{+} / \mathrm{CD}^{+}$ratio and percentage of NK cells. These results indicate that the percentage of $\mathrm{CD}^{+}{ }^{+} \mathrm{T}$ lymphocytes is a promising biomarker in predicting SE occurrence among patients with severe sepsis. The recirculation of $\mathrm{CD}^{+} \mathrm{T}$ lymphocytes may be responsible for the percentage of $\mathrm{CD}^{+} \mathrm{T}$ lymphocytes decreasing in the peripheral blood of patients with sepsis. This recirculation may be associated with the generation of stress hormones, cytokines and other humoral factors, including prostaglandin E2- $\alpha$, cortisol and interleukin-10 $(55,56)$, which is supported by previous studies revealing a rapid decrease in circulating $\mathrm{CD}^{+} \mathrm{T}$ lymphocytes following the experimental administration of endotoxin and an observed increase in the concentration of these cells in the thoracic ducts of patients with systemic inflammatory response syndrome $(57,58)$.

The present study provides novel insights into the role of $\mathrm{CD}^{+} \mathrm{T}$ lymphocytes during SE, but has several limitations. Poor nutritional status was typical and varied among patients with severe sepsis. Malnutrition has marked consequences on the immune response that may affect results. Furthermore, the diagnosis of SE may have been affected by a negative mood in patients. In conclusion, the present study provides a unique insight into the status of the immune system in SE. SE leads to higher mortality rates in patients with severe sepsis, and immune imbalance has an important role in this increase in mortality rates. The current study indicates that the proportion of $\mathrm{CD} 4^{+} \mathrm{T}$ lymphocytes present in the blood of patients with severe sepsis is a powerful predictor of SE. However, additional investigation is required to elucidate the pathogenesis of SE.

\section{Acknowledgements}

The authors of the current study thank all biotechnicians of the clinical laboratories in Zhongshan Hospital Xiamen University for their technical support. The present study was supported by grants from the National Natural Science Foundation of China (grant nos. 81071529 and 81272105).

\section{References}

1. Sprung CL, Peduzzi PN, Shatney $\mathrm{CH}$, Schein RM, Wilson MF, Sheagren JN and Hinshaw LB: Impact of encephalopathy on mortality in the sepsis syndrome. The Veterans Administration Systemic Sepsis Cooperative Study Group. Crit Care Med 18: 801-806, 1990.

2. Eidelman LA, Putterman D, Putterman C and Sprung CL: The spectrum of septic encephalopathy. Definitions, etiologies, and mortalities. JAMA 275: 470-473, 1996.

3. Straver JS, Keunen RW, Stam CJ, Tavy DL, de Ruiter GR, Smith SJ, Thijs LG, Schellens RG and Gielen G: Nonlinear analysis of EEG in septic encephalopathy. Neurol Res 20: 100-106, 1998

4. Schraag S: Studying septic encephalopathy: What animal models can predict. Intensive Care Med 29: 667-668, 2003.

5. Eggers V, Fügener K, Hein OV, Rommelspacher H, Heyes MP, Kox WJ and Spies CD: Antibiotic-mediated release of tumour necrosis factor alpha and norharman in patients with hospital-acquired pneumonia and septic encephalopathy. Intensive Care Med 30: 1544-1551, 2004.

6. Angel MJ and Young GB: Metabolic encephalopathies. Neurol Clin 29: 837-882, 2011.

7. Koo DJ, Jackman D, Chaudry IH and Wang P: Adrenal insufficiency during the late stage of polymicrobial sepsis. Crit Care Med 29: 618-622, 2001.

8. Tsao N, Hsu HP, Wu CM, Liu CC and Lei HY: Tumour necrosis factor-alpha causes an increase in blood-brain barrier permeability during sepsis. J Med Microbiol 50: 812-821, 2001

9. Basler T, Meier-Hellmann A, Bredle D and Reinhart K: Amino acid imbalance early in septic encephalopathy. Intensive Care Med 28: 293-298, 2002.

10. Deng YY, Fang M, Zhu GF, Zhou Y and Zeng HK: Role of microglia in the pathogenesis of sepsis-associated encephalopathy. CNS Neurol Disord Drug Targets 12: 720-725, 2013.

11. Munford RS and Pugin J: Normal responses to injury prevent systemic inflammation and can be immunosuppressive. Am J Respir Crit Care Med 163: 316-321, 2001.

12. Oberholzer A, Oberholzer C and Moldawer LL: Sepsis syndromes: Understanding the role of innate and acquired immunity. Shock 16: 83-96, 2001.

13. Abraham E and Singer M: Mechanisms of sepsis-induced organ dysfunction. Crit Care Med 35: 2408-2416, 2007.

14. Rittirsch D, Flierl MA and Ward PA: Harmful molecular mechanisms in sepsis. Nat Rev Immunol 8: 776-787, 2008.

15. Luyt CE, Combes A, Deback C, Aubriot-Lorton $\mathrm{MH}$ Nieszkowska A, Trouillet JL, Capron F, Agut H, Gibert C and Chastre J: Herpes simplex virus lung infection in patients undergoing prolonged mechanical ventilation. Am J Respir Crit Care Med 175: 935-942, 2007.

16. Kollef KE, Schramm GE, Wills AR, Reichley RM, Micek ST and Kollef MH: Predictors of 30-day mortality and hospital costs in patients with ventilator-associated pneumonia attributed to potentially antibiotic-resistant gram-negative bacteria. Chest 134: 281-287, 2008. 
17. Limaye AP, Kirby KA, Rubenfeld GD, Leisenring WM, Bulger EM, Neff MJ, Gibran NS, Huang ML, Santo Hayes TK, Corey L and Boeckh M.: Cytomegalovirus reactivation in critically ill immunocompetent patients. JAMA 300: 413-422, 2008.

18. Schwartz $\mathrm{M}$ and Baruch $\mathrm{K}$ : The resolution of neuroinflammation in neurodegeneration: Leukocyte recruitment via the choroid plexus. EMBO J 33: 7-22, 2014.

19. Tian L, Ma L, Kaarela T, and Li Z: Neuroimmune crosstalk in the central nervous system and its significance for neurological diseases. J Neuroinflammation 9: 155, 2012.

20. Neumann H: Control of glial immune function by neurons. Glia 36: 191-199, 2001.

21. Levy MM, Fink MP, Marshall JC, Abraham E, Angus D, Cook D, Cohen J, Opal SM, Vincent JL and Ramsay G; International Sepsis Definitions Conference: 2001 SCCM/ESICM/ACCP/ATS/SIS International Sepsis Definitions Conference. Intensive Care Med 29: 530-538, 2003.

22. Cotena S and Piazza O: Sepsis-associated encephalopathy. Transl Med UniSa 2: 20-27,2012.

23. Dal-Pizzol F, Tomasi CD and Ritter C: Septic encephalopathy: Does inflammation drive the brain crazy? Rev Bras Psiquiatr 36: 251-258, 2014.

24. Dellinger RP,Levy MM, Rhodes A, Annane D, Gerlach H, Opal SM, Sevransky JE, Sprung CL, Douglas IS, Jaeschke R, et al; Surviving Sepsis Campaign Guidelines Committee including the Pediatric Subgroup: Surviving sepsis campaign: International guidelines for management of severe sepsis and septic shock: 2012. Crit Care Med 41: 580-637, 2013.

25. Karmen A, Worblewski F and Landue JS: Transaminases activity in human blood. J Clin Invest 34: 126-131, 1955.

26. Milbrandt EB and Angus DC: Bench-to-bedside review: Critical illness-associated cognitive dysfunction - mechanisms, markers, and emerging therapeutics. Crit Care 10: 238, 2006.

27. Ebersoldt M, Sharshar T and Annane D: Sepsis-associated delirium. Intensive Care Med 33: 941-950, 2007.

28. Zhang LN, Wang XT, Ai YH, Guo QL, Huang L, Liu ZY and Yao B: Epidemiological features and risk factors of sepsis-associated encephalopathy in intensive care unit patients: 2008-2011. Chin Med J (Engl) 125: 828-831, 2012.

29. Zauner C, Gendo A, Kramer L, Kranz A, Grimm G and Madl C: Metabolic encephalopathy in critically ill patients suffering from septic or nonseptic multiple organ failure. Crit Care Med 28: 1310-1315, 2000.

30. Taylor SL, Morgan DL, Denson KD, Lane MM and Pennington LR: A comparison of the Ranson, Glasgow, and APACHE II scoring systems to a multiple organ system score in predicting patient outcome in pancreatitis. Am J Surg 189: 219-222, 2005.

31. Bone RC, Sprung CL and Sibbald WJ: Definitions for sepsis and organ failure. Crit Care Med 20: 724-726, 1992.

32. Babior BM: NADPH oxidase: An update. Blood 93: 1464-1476, 1999.

33. Wang CX and Shuaib A: Involvement of inflammatory cytokines in central system injury. Prog Neurobiol 67: 161-172, 2002.

34. Choi SH, Lee DY, Kim SU and Jin BK: Thrombin-induced oxidative stress contributes to the death of hippocampal neurons in vivo: Role of microglial NADPH oxidase. J Neurosci 25: 4082-4090, 2005.

35. Sprung CL, Cerra FB, Freund HR, Schein RM, Konstantinides FN, Marcial EH and Pena M: Amino acid alterations and encephalopathy in the sepsis syndrome. Crit Care Med 19: 753-757, 1991.

36. Kadoi Y and Saito S: An alteration in the gamma-aminobutyric acid receptor system in experimentally induced septic shock in rats. Crit Care Med 24: 298-305, 1996.

37. Nguyen DN, Spapen H, Su F, Schiettecatte J, Shi L, Hachimi-Idrissi S and Huyghens L: Elevated serum levels of S-100beta protein and neuron-specific enolase are associated with brain injury in patients with severe sepsis and septic shock. Crit Care Med 34: 1967-1974, 2006.

38. Piazza O, Cotena S, De Robertis E, Caranci F and Tufano R: Sepsis associated encephalopathy studied by MRI and cerebral spinal fluid S100B measurement. Neurochem Res 34: 1289-1292, 2009.

39. Piazza O, Russo E, Cotena S, Esposito G and Tufano R: Elevated S100B levels do not correlate with the severity of encephalopathy during sepsis. Br J Anaesth 99: 518-521, 2007.

40. van den Boogaard M, Ramakers BP, van Alfen N, van der Werf SP Fick WF, Hoedemaekers CW, Verbeek MM, Schoonhoven L, van der Hoeven JG and Pickkers P: Endotoxemia-induced inflammation and the effect on the human brain. Crit Care 14: R81, 2010.
41. Omari KM and Dorovini-Zis K: CD40 expressed by human brain endothelial cells regulates $\mathrm{CD} 4^{+} \mathrm{T}$ cell adhesion to endothelium. J Neuroimmunol 134: 166-178, 2003.

42. Sankowski R, Mader S and Valdés-Ferrer SI: Systemic inflammation and the brain: novel roles of genetic, molecular, and environmental cues as drivers of neurodegeneration. Front Cell Neurosci 9: 28, 2015.

43. Hotchkiss RS, Tinsley KW, Swanson PE, Schmieg RE Jr, Hui JJ, Chang KC, Osborne DF, Freeman BD, Cobb JP, Buchman TG and Karl IE: Sepsis-induced apoptosis causes progressive profound depletion of $\mathrm{B}$ and $\mathrm{CD} 4^{+} \mathrm{T}$ lymphocytes in humans. J Immunol 166: 6952-6963, 2001.

44. Roth G, Moser B, Krenn C, Brunner M, Haisjack1 M, Almer G, Gerlitz S, Wolner E, Boltz-Nitulescu G and Ankersmit HJ: Susceptibility to programmed cell death in T-lymphocytes from septic patients: A mechanism for lymphopenia and Th2 predominance. Biochem Biophys Res Commun 308: 840-846, 2003.

45. Boomer JS, To K, Chang KC, Takasu O, Osborne DF, Walton AH, Bricker TL, Jarman SD II, Kreisel D, Krupnick AS, et al: Immunosuppression in patients who die of sepsis and multiple organ failure. JAMA 306: 2594-2605, 2011.

46. Sunkara B, Bheemreddy S, Lorber B, Lephart PR, Hayakawa K, Sobel JD, Kaye KS and Marchaim D: Group B Streptococcus infections in non-pregnant adults: The role of immunosuppression. Int J Infect Dis 16: e182-e186, 2012.

47. Ferguson NR, Galley HF and Webster NR: T helper cell subset ratios in patients with severe sepsis. Intensive Care Med 25: 106-109, 1999.

48. Cheadle WG, Pemberton RM, Robinson D, Livingston DH, Rodriguez JL and Polk HC Jr: Lymphocyte subset responses to trauma and sepsis. J Trauma 35: 844-849, 1993.

49. Wakefield CH, Carey PD, Foulds S, Monson JR and Guillou PJ: Changes in major histocompatibility complex class II expression in monocytes and $\mathrm{T}$ cells of patients developing infection after surgery. Br J Surg 80: 205-209, 1993.

50. Chalifour A, Jeannin P, Gauchat JF, Blaecke A, Malissard M, N'Guyen T, Thieblemont N and Delneste Y: Direct bacterial protein PAMP recognition by human NK cells involves TLRs and triggers alpha-defensin production. Blood 104: 1778-1783, 2004.

51. Andaluz-Ojeda D, Iglesias V, Bobillo F, Almansa R, Rico L, Gandía F, Loma AM, Nieto C, Diego R, Ramos E, et al: Early natural killer cell counts in blood predict mortality in severe sepsis. Crit Care 15: R243, 2011.

52. Anduluz-Ojeda D, Iglesias V, Bobillo F, Almansa R, Rico L, Gandía F, Loma AM, Nieto C, Diego R, Ramos E, et al: Early natural killer cell counts in blood predict mortality in severe sepsis. Crit Care 15: R243, 2011.

53. Markwart R, Condotta SA, Requardt RP, Borken F, Schubert K, Weigel C, Bauer M, Griffith TS, Förster M, Brunkhorst FM, et al: Immunosuppression after sepsis: Systemic inflammation and sepsis induce a loss of naïve T-cells but no enduring cell-autonomous defects in T-cell function. PLoS One 9: e115094, 2014.

54. de Pablo R, Monserrat J, Reyes E, Diaz-Martin D, Rodriguez Zapata M, Carballo F, de la Hera A, Prieto A and Alvarez-Mon M: Mortality in patients with septic shock correlates with anti-inflammatory but not proinflammatory immunomodulatory molecules. J Intensive Care Med 26: 125-132, 2011.

55. Menges T, Engel J, Welters I, Wagner RM, Little S, Ruwoldt R, Wollbrueck $M$ and Hempelmann G: Changes in blood lymphocyte populations after multiple trauma: Association with posttraumatic complications. Crit Care Med 27: 733-740, 1999.

56. Sarlis NJ, Chanock SJ and Nieman LK: Cortisolemic indices predict severe infections in Cushing syndrome due to ectopic production of adrenocorticotropin. J Clin Endocrinol Metab 85: 42-7, 2000.

57. Toft P, Hokland M, Hansen TG, and Tønnesen E: Changes in lymphocyte subpopulations and adhesion/activation molecules following endotoxemia and major surgery. APMIS 103: 261-266, 1995.

58. Lemaire LC, van Deventer SJ, van Lanschot JJ, Meenan J and Gouma DJ: Phenotypical characterization of cells in the thoracic duct of patients with and without systemic inflammatory response syndrome and multiple organ failure. Scand J Immunol 47: 69-75, 1998. 